\title{
Potential Effects of Forest Fires on Streamflow in the Enipeas River Basin, Thessaly, Greece
}

\author{
Stamatios-Christos Batelis • Ioannis Nalbantis
}

Received: 26 November 2013 / Accepted: 13 December 2013 / Published online: 24 April 2014

(C) Springer International Publishing Switzerland 2014

\begin{abstract}
Hydrological effects of forest fires have been extensively studied with main emphasis on floods, whereas streamflow at coarse temporal scales (e.g., monthly) has generally drawn less attention. Yet, accounting for changes after fires, until the return to pre-fire conditions, is vital in water resources management. This paper presents a study on the hydrological effect of hypothetical forest fires in a Mediterranean basin, the Enipeas river basin $\left(439 \mathrm{~km}^{2}\right)$ in Thessaly, Greece. The water balance of the basin is assessed for pre-fire conditions and after hypothetical fire events. For this, the hydrological model SWAT (Soil and Water Assessment Tool) is used, which allows for reliable predictions of runoff and other water balance components. For post-fire conditions, knowledge from earlier studies is exploited so as to modify key model parameters, such as the Curve Number of the well-known SCS-CN method. The daily temporal scale is employed, which is sufficiently fine to allow for accurate representation of the physical processes. Monthly discharge data are used for model calibration and validation. Three fire scenarios are formulated, based on known features of fires in the Mediterranean region for similar topography and land uses. The following effects of forest fires are quantified: (1) changes in mean values of the total runoff and runoff components on the monthly, three-month, six-month and annual basis; and (2) the effect on hydrological drought classification through using a drought index known as the Streamflow Drought Index (SDI).
\end{abstract}

Keywords Forest fires $\cdot$ Streamflow $\cdot$ SWAT $\cdot$ Thessaly $\cdot$ Drought $\cdot$ Streamflow Drought Index (SDI)

\section{Introduction}

Although the hydrological effects of forest fires have been the subject of research since the 1950s (Rycroft 1947; Colman 1951), large differences and conflicts in reported results

\footnotetext{
S.-C. Batelis $\cdot$ I. Nalbantis $(\square)$

Laboratory of Reclamation Works and Water Resources Management, School of Rural and Surveying Engineering, National Technical University of Athens, Heroon Polytechniou 9, 15780 Zographou, Greece e-mail: nalbant@central.ntua.gr

S.-C. Batelis

e-mail: st.batelis@gmail.com
} 
precluded the formation of a solid body of knowledge on the subject. This is expected, since factors influencing the related physical phenomena are multiple and show large variations (e.g., vegetation diversity). The prime research tools used in this research field are experimental methods and hydrological modelling. For example, Scott (1993) experimentally studied the effect of fires in four mountainous South African basins using the paired catchment method. He found that annual streamflow is marginally increased in all basins, while two basins exhibited a large increase of stormflow; the latter effect was attributed to the increase of overland flow and the reduction of infiltration. Brown et al. (2005) reviewed experimental studies on the fire effect on the basin water yield at the annual and seasonal time scales, as well as changes in flow duration curves.

Knowledge on the subject has not been exploited in large scale water resources management studies. This is most probably due to the fact that large drainage basins are rarely hit by forest fires to a spatial extent that covers a significant part of their area. On the other hand, the effects of minor fire events are practically indiscernible in these basins. As a result, hydrological simulation that generalises information from small experimental basins to large basins remains the only viable alternative. Simulation is used in this study.

The aim of this work is two-fold: (1) the illustration of the practical usage of a hydrological simulation tool, the Soil Water Assessment Tool or SWAT (Arnold et al. 1999; Neitsch et al. 1999; 2005), for the study of the hydrological effects of large scale forest fires in an environment such as the Mediterranean one, which is frequently exposed to fires; and (2) the quantification of the fire effect on the basin water yield at coarse time scales, i.e., monthly and annual. Also, special attention is paid to the interference of the fire effect with hydrological drought classification. For this, the Streamflow Drought Index (SDI) for hydrological drought characterisation, recently proposed by Nalbantis and Tsakiris (2009), is employed.

\section{Methodology}

\subsection{The Soil Water Assessment Tool (SWAT) and Its Data Requirements}

The Soil Water Assessment Tool (SWAT) has been extensively applied to many parts worldwide including basins in the vicinity of our test basin (Pikounis et al. 2003; Gikas et al. 2006; Boskidis et al. 2010; 2011).

The hydrological cycle is represented at the spatial scale of hydrologically homogeneous units termed as the Hydrological Response Units (HRUs). The studied drainage basin is first divided into sub-basins which are further sub-divided into HRUs based on information on soils, land use and ground slope. The basic hydrological processes are modelled, which are snow accumulation and melting, infiltration, direct surface runoff, unsaturated flow in the root zone, saturated flow in a shallow unconfined and a deep confined aquifer, groundwater recharge and baseflow. Direct surface runoff is estimated through a modified version of the well-known SCS-CN method (U.S. Soil Conservation Service 1986) as

$$
Q= \begin{cases}\frac{\left(P-I_{\mathrm{a}}\right)^{2}}{P-I_{\mathrm{a}}+S} & P>I_{\mathrm{a}} \\ 0 & P \leq I_{\mathrm{a}}\end{cases}
$$

where $Q$ is the cumulative direct surface runoff depth [mm], $P$ is the cumulative rainfall depth from the beginning of the studied storm [mm], $S$ is the potential maximum 
retention [mm], and $I_{\mathrm{a}}$ denotes the initial abstractions before ponding [mm]. The quantity $S$ is estimated from a dimensionless parameter, the Curve Number or $\mathrm{CN}$, as

$$
S=254\left(\frac{100}{\mathrm{CN}}-1\right)
$$

where $S$ is given in $\mathrm{mm}$.

Modification of $S$ for inter-storm periods allows for continuous time simulation, which is not feasible within the classical SCS-CN method.

Flow in the unsaturated zone is represented as the downward vertical movement in a number of soil layers. When the $i$-th layer is saturated, downward flow $O_{i}$ occurs, which is

$$
O_{i}=\mathrm{SW}_{0 i}\left[1-\exp \left(\frac{-\Delta t}{\mathrm{TT}}\right)\right]
$$

where $\mathrm{SW}_{0 i}$ is the initial soil water, $\Delta t$ is the time step, and TT is the travel time within the $i$-th layer which is calculated based on the hydraulic conductivity under unsaturated conditions.

Interflow, $q_{\text {lat }}$, is estimated as the sum of contributions of conceptual hillslopes through

$$
q_{\text {lat }}=0.024 \frac{2 S K_{\mathrm{s}} \sin (a)}{\Theta_{\mathrm{d}} L}
$$

where $S$ is soil water less the field capacity, $K_{\mathrm{s}}$ is the saturated hydraulic conductivity, $L$ is the length of the watercourse, $\sin (a)$ is the slope of the hillslope, and $\Theta_{\mathrm{d}}$ is the drainable porosity of the soil.

The groundwater discharge from the shallow aquifer, or baseflow, is estimated assuming Darcian flow and keeping track of the water balance of this aquifer. No contribution to runoff from the deep aquifer is considered.

Potential evapotranspiration can be estimated via three alternative methods: PenmanMonteith (Monteith 1965), Hargreaves (Hargreaves and Samani 1985) and Priestley-Taylor (1972).

\subsection{The Streamflow Drought Index (SDI)}

Drought is known to be a slowly developing phenomenon, typically characterised by its severity or intensity, its onset and duration, and its frequency of occurrence. Since the onset and duration of a drought episode are highly uncertain, and thus difficult to identify, coarse time steps are sufficient for drought characterisation. The typical time step used is monthly, which is employed also in this study.

Drought indices are commonly used to characterise drought severity; these are based on one or more determinants. In the classical approach for drought characterisation, the onset and end of a drought episode are respectively defined as the time when a drought index falls below or rises above a certain truncation level. Determinants for successive non-overlapping time intervals are used in this approach. Another approach has been proposed recently (Tsakiris and Vangelis 2005; Tsakiris et al. 2007; Nalbantis and Tsakiris 2009) which employs overlapping time intervals of duration of three months (October-December), six months (OctoberMarch), nine months (October-June) and twelve months (October-September). These periods are defined as the reference periods.

Assuming that a time series of monthly streamflow volume is available for $N$ hydrological years, the cumulative streamflow volume $V_{i, k}$ for each hydrological year $i$ and reference period 
$k$ is obtained, where $i=1,2,3, \ldots, N$, and $k=1$ for October-December, $k=2$ for OctoberMarch, $k=3$ for October-June, and $k=4$ for October-September.

The Streamflow Drought Index (SDI) is defined for each reference period $k$ of the $i$-th hydrological year as

$$
\mathrm{SDI}_{i, k}=\frac{V_{i, k}-\bar{V}_{k}}{s_{k}} i=1,2, \ldots, N \quad k=1,2,3,4
$$

where $\overline{V_{k}}$ and $s_{k}$ are respectively the mean and the standard deviation of cumulative streamflow volumes of reference period $k$.

Based on SDI, five classes of hydrological drought are defined, which are denoted by integer numbers as follows: 0 (non-drought with SDI $\geq 0.0$ ), 1 (mild drought with $-1.0 \leq$ $\mathrm{SDI}<0.0$ ), 2 (moderate drought with $-1.5 \leq \mathrm{SDI}<-1.0$ ), 3 (severe drought with $-2.0 \leq \mathrm{SDI}<$ -1.5 ) and 4 (extreme drought with SDI $<-2.0$ ). These class bounds presupposed normality.

The fact that for small basins and short reference periods (e.g., October-December) the streamflow probability distribution is usually skewed may require normalisation through using distributions, such as Gamma or Log-normal. Also, the problem of treating intermittent or ephemeral flows is of importance, as discussed by Nalbantis and Tsakiris (2009).

\subsection{The Testing Framework}

A testing framework is set up and comprises the following steps: (1) the SWAT model is calibrated and validated based on existing hydrological data; (2) scenarios of hypothetical forest fires are formulated which comply with fire characteristics that are typical of the study region; (3) the SWAT model is applied to simulate runoff in post-fire hydrological conditions after changing estimated values of key model parameters, such as the Curve Number (see Table 1), through exploiting knowledge from earlier studies (Cerrelli 2005; Goodrich et al. 2005; Livingston et al. 2005; Solt and Muir 2006; Higginson and Jarnecke 2007; Nalbantis and Lymperopoulos 2012) assuming that for each scenario the included area is burnt to the ground; (4) numerical criteria for result evaluation are set up or selected; these allow the comparison between pre-fire and post-fire values of runoff and its components; (5) the SDI index is calculated for pre- and post-fire conditions; its values allow the drought classification for the period of data availability, thus quantifying the effect of fire on drought characterisation.

Table 1 Values of Curve Number for normal antecedent moisture conditions (CNII) for pre-fire and post-fire conditions for each type of land use and soil (A, B, C, D).

\begin{tabular}{|c|c|c|c|c|c|c|}
\hline \multirow[t]{2}{*}{ No } & \multirow[t]{2}{*}{ Land use } & \multirow[t]{2}{*}{ SWAT Land use } & \multicolumn{4}{|c|}{ CNII Pre-fire } \\
\hline & & & A & B & $\mathrm{C}$ & $\mathrm{D}$ \\
\hline 1 & Non-irrigated arable land & WWHT & 39 & 66 & 73 & 76 \\
\hline 2 & Broad-leaved forest & FRSD & 45 & 66 & 77 & 83 \\
\hline 3 & Sclerophyllous vegetation & FRST & 36 & 60 & 73 & 79 \\
\hline \multirow[t]{3}{*}{4} & Transitional woodland-shrub & RNGE & 49 & 69 & 79 & 84 \\
\hline & & & \multicolumn{4}{|c|}{ CNII Post-fire } \\
\hline & All & All & 77 & 86 & 91 & 94 \\
\hline
\end{tabular}




\section{Study Area}

\subsection{Description of the Study Area}

The Enipeas river constitutes one of the major tributaries of the Pinios river in Thessaly, Greece. A dam has been planned at the site of Paleoderli. The basin upstream of the dam site is considered in this study. Its surface area is $439 \mathrm{~km}^{2}$, its ground elevation ranges from $275 \mathrm{~m}$ to $1622 \mathrm{~m}$ with a mean value of $644 \mathrm{~m}$, while the length of the main watercourse is $36.8 \mathrm{~km}$. Information on ground elevation and the hydrographic network is depicted in Fig. 1.

\subsection{Data Used}

Three raingauges are used in which the common period of data availability is from 1975-76 to 1986-87. Statistical homogeneity of precipitation data was verified via the double mass curve method (Batelis 2012). Spatially averaged precipitation depths are obtained through using the Thiessen polygon method. Correction for elevation differences is also performed. The rate of precipitation increase per unit of elevation difference was estimated from observed data at $66 \mathrm{~mm}$ per $100 \mathrm{~m}$ elevation difference at the annual time basis. The Hargreaves method is used for the estimation of potential evapotranspiration. For this, data for air temperature from one

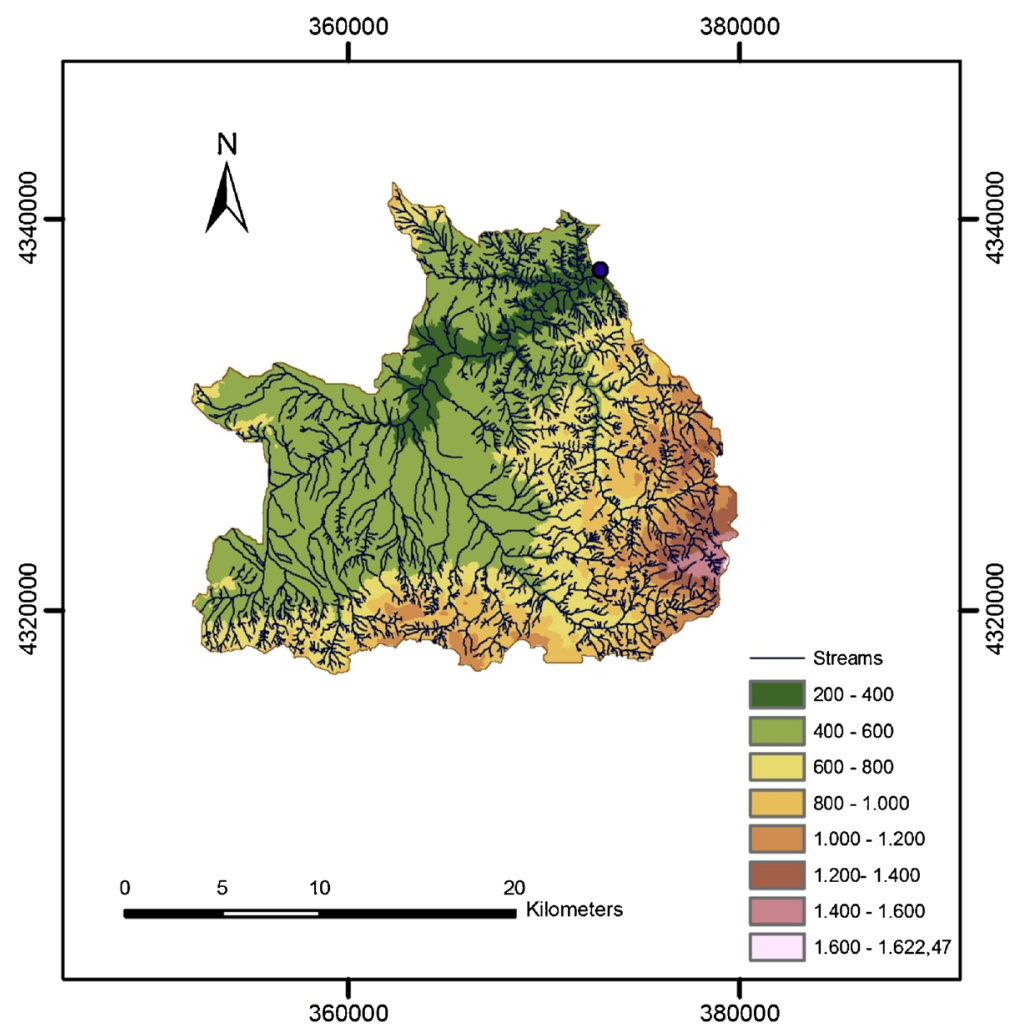

Fig. 1 Ground elevation and hydrographic network of the Enipeas river basin at Paleoderli (Greek Geodetic Reference System '87) 
meteorological station are employed. The regional value of the lapse rate is found to be $-0.55^{\circ} \mathrm{C}$ per $100 \mathrm{~m}$.

Land use data are drawn from maps 1:100 000 of the Corine project. Cultivated areas and areas with low vegetation are predominant with respective percentages of area equal to $50 \%$ and $35 \%$. Eleven land uses are identified which correspond to the SWAT land uses depicted in Fig. 2. Four soil categories are identified according to the classification used in SWAT (cambisols, fluvisols, luvisols and regosols); these are shown in Fig. 3.

\section{Results}

\subsection{Model Calibration and Validation}

A model is set up assuming the following: (1) the basin is subdivided into 27 subbasins and 377 HRUs using land use, soils and ground slope as determinants, and a common threshold of percentage of area equal to $5 \%$; (2) all input data are expressed as total daily depths; (3) the simulation time step is one day; (4) the simulated daily streamflows are aggregated into monthly average flow rates which are then compared to observed values.

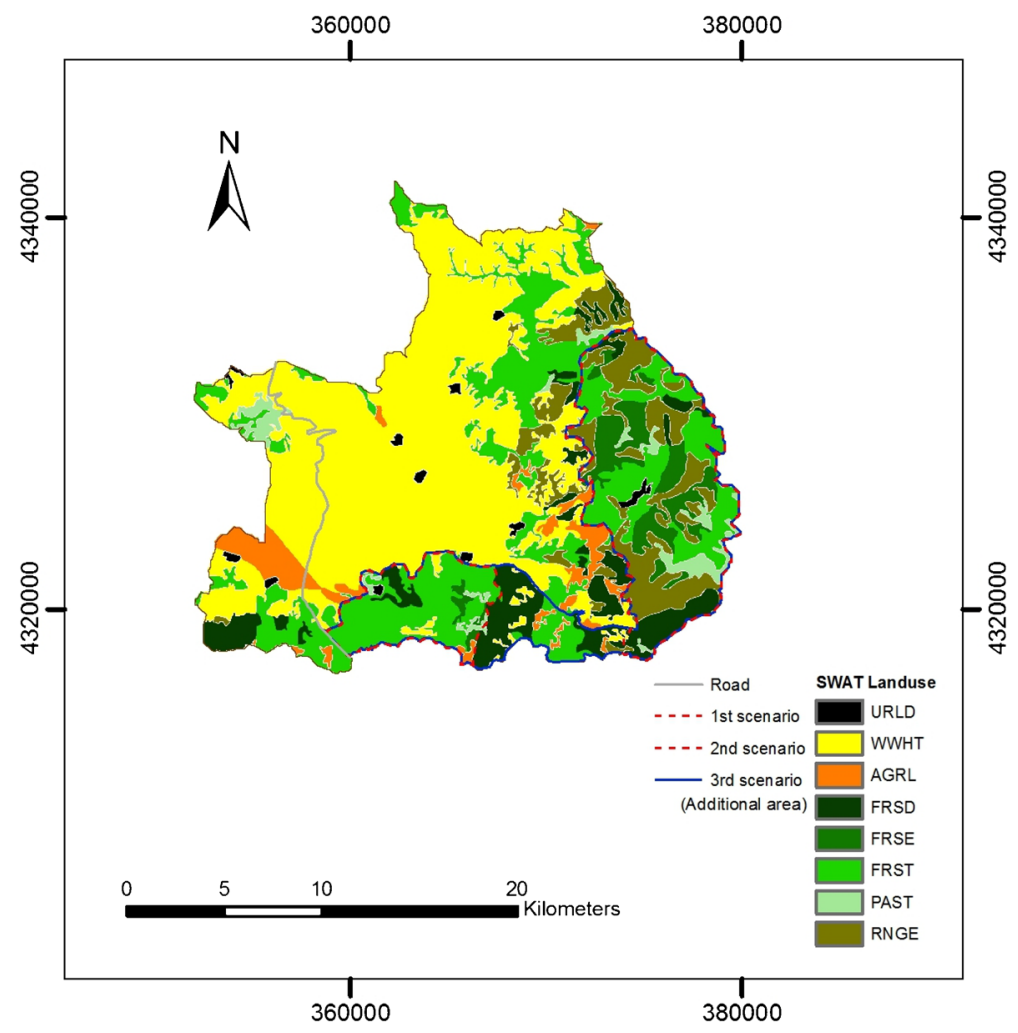

Fig. 2 Land uses in the Enipeas river basin following the SWAT classification (Greek Geodetic Reference System '87); also, burnt areas for the three forest fire scenarios are shown 


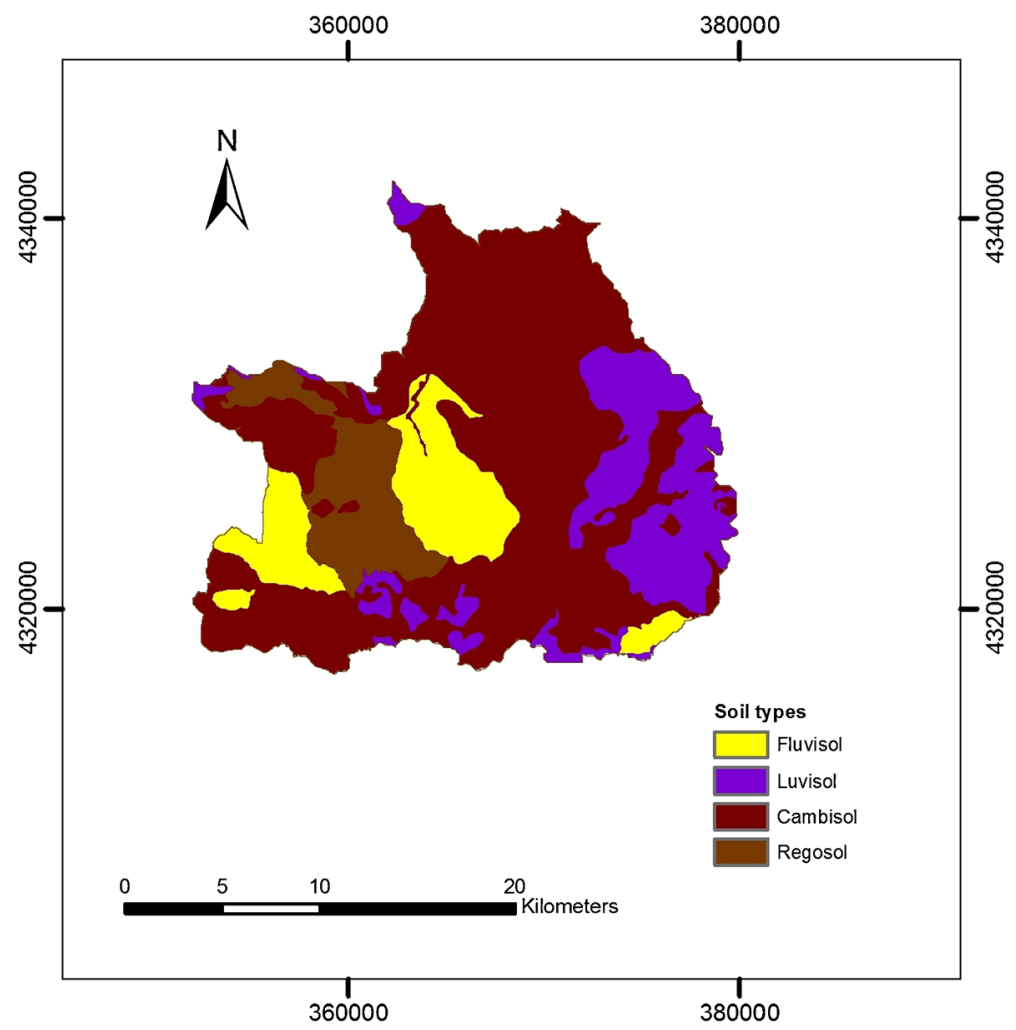

Fig. 3 Soil categories in the Enipeas river basin following the SWAT classification

Model calibration is performed manually based on data from a five-year period, while validation is also based on data of another five-year period. The Nash-Sutcliffe efficiency (Nash and Sutcliffe 1970) is 0.762 in calibration and 0.751 in validation (Fig. 4).

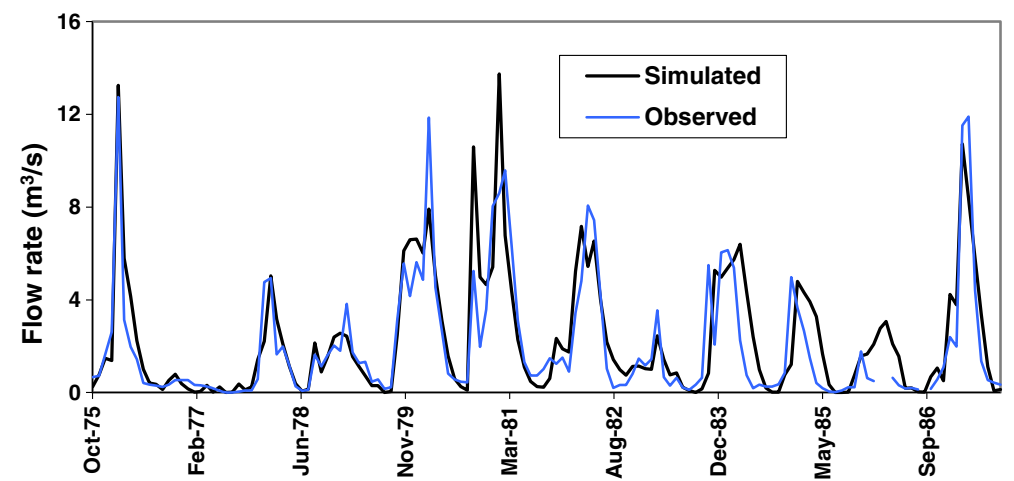

Fig. 4 Comparison of simulated and observed flow rate data 


\subsection{Effect of Forest Fires on Streamflow and Basin Water balance}

Three scenarios of forest fires are constructed which realistically represent forest fires in the Greek territory. Specifically, coniferous forests, transitory forest-scrub areas and sclerofyllous vegetation are particularly vulnerable to fire in contrast to forests with broad-leaved trees. In cultivated areas, fires are considered far easier to combat. Also, the existence of roads is a critical factor for combating fires. It is found that forests are developed in areas with high slope $(>15 \%)$ which favours the progression of fires.

The calibrated SWAT model is applied to the historical time series of precipitation and potential evapotranspiration by changing the Curve Number in areas that are assumed to be burnt.

In Scenario 1, the Southern part of the basin is assumed to be burnt in which sclerofyllous vegetation and small patches of broad-leaved trees are encountered. The fire is assumed to be stopped at the boundary with cultivated areas (to the North), broad-leaved tree forest (to the East), and the provincial road between the cities of Lamia and Domokos (to the West). To the South the fire is considered up to the watershed divide. In this scenario $26 \mathrm{~km}^{2}$ or $6 \%$ of the total basin area are burnt.

In Scenario 2, the Eastern part of the basin is burnt which constitutes the warmer and dryer part of the basin. It encompasses forests of coniferous trees (mainly pine trees) and transitory forest-scrub areas with sclerofyllous vegetation which is particularly flammable. All other categories of vegetation in the area are also considered to be burnt. Again, boundaries with cultivated areas and the line of reduction or break of ground slope help delineate the burnt area from the North and West, while the watershed divide is considered as the boundary from the East and South. The burnt area is $88 \mathrm{~km}^{2}$, or $20 \%$ of the basin surface area.

In Scenario 3, an extreme situation is hypothesised which involves burnt areas of both scenarios (1 and 2) together with a small intermediate area between the burnt areas of those scenarios. Again, ground slope helps delineate this additional area. In total, $131 \mathrm{~km}^{2}$ or $30 \%$ of the basin surface area is assumed to be burnt.

As expected, the first scenario resulted in small changes in streamflow at the basin outlet. Simulated hydrographs for pre- and post-fire conditions reveal small increases for high flows and decreases for low flows. These changes are due to the increase in direct runoff and the reduction of infiltration. Such phenomena are consistent with physical reality as revealed through experimental studies mentioned in the Introduction. The mean flow rate of the whole studied period for the total basin area $\left(2.295 \mathrm{~m}^{3} / \mathrm{s}\right)$ increased by $1.34 \%$ or $0.031 \mathrm{~m}^{3} / \mathrm{s}$. The burnt HRUs show an increase in their spatially accumulated streamflow volume equal to $15.5 \%$ for the whole simulation period. This is a direct implication of the changes in the Curve Number shown in Table 1. The impact on the total streamflow of the basin is, however, low due to the limited surface area that was burnt under this scenario. To investigate the impact on high flows, peak monthly flow rates above $4 \mathrm{~m}^{3} / \mathrm{s}$ are isolated. Of 13 peaks that are identified, five showed a flow decrease with its maximum equal to $7.25 \%$ or $0.48 \mathrm{~m}^{3} / \mathrm{s}$, while in the remaining eight peaks an increase is manifested with its maximum equal to $13.3 \%$ or $1.41 \mathrm{~m}^{3} / \mathrm{s}$. On the average, all peaks show an increase by $2.70 \%$ or $0.263 \mathrm{~m}^{3} / \mathrm{s}$. High relative changes (up to $230 \%$ ) are observed in months with low flows. In summer months in particular, negative changes are commonly found.

In Scenario 2, small changes in streamflow are also found. More specifically, simulated hydrographs for pre- and post-fire conditions reveal small increases for high flows and decreases for low flows, which are, however, higher than those of Scenario 1. The average flow rate of the whole period increased by $3.53 \%$ or $0.081 \mathrm{~m}^{3} / \mathrm{s}$ for the total basin area. The increase in total streamflow of the burnt HRUs is $11.4 \%$ for the whole simulation period. This 
has again a low impact on the total streamflow of the basin due to the limited burnt surface area. Only three of the 13 peaks of monthly flow rates above $4 \mathrm{~m}^{3} / \mathrm{s}$ show decreases with a maximum of $11.0 \%$ or $0.729 \mathrm{~m}^{3} / \mathrm{s}$. The remaining ten peaks manifest increases with a maximum equal to $28.7 \%$ or $3.04 \mathrm{~m}^{3} / \mathrm{s}$. The average increase is $6.75 \%$ or $0.562 \mathrm{~m}^{3} / \mathrm{s}$. Low flow changes are similar to those of Scenario 1.

As expected, in Scenario 3 changes in streamflow between pre- and post-fire conditions (Fig. 5) are larger than those of the previous scenarios, especially for high flows. The average flow rate of the whole period is increased by $4.6 \%$ or $0.105 \mathrm{~m}^{3} / \mathrm{s}$ for the total basin area. The increase in total streamflow of the burnt HRUs is $11.7 \%$ for the whole simulation period. Yet, a significant impact on total streamflow of the basin is found. Only two of the 13 peaks of monthly flow rates above $4.0 \mathrm{~m}^{3} / \mathrm{s}$ show a decrease this time with a maximum equal to $11.84 \%$ or $0.784 \mathrm{~m}^{3} / \mathrm{s}$. The remaining eleven peaks manifest increases with a maximum of $38.5 \%$, or $4.1 \mathrm{~m}^{3} / \mathrm{s}$. The average increase is $9.13 \%$, or $0.786 \mathrm{~m}^{3} / \mathrm{s}$.

To investigate the within-year impact of fires, changes of flow rate are calculated between the pre-fire conditions and post-fire conditions of each scenario. These are depicted in Fig. 6 in absolute, as well as in relative values. The following can be observed in this figure: (1) monthly flow differences of post-fire flows from their pre-fire values increase with the increase of burnt area, both in absolute and relative terms, although for summer months the absolute changes are small; this result is expected since the increase of burnt area results in higher surface runoff and lower opportunity for evapotranspiration loss in the burnt areas; (2) negative changes are found for months from March to June due to the increased values of interflow in these months; (3) the larger absolute increases concern the period from September to November, with October showing the maximum increase; (4) relative increases appear to vary more or less in accordance with absolute increases.

Studying mean three-month values of flow rate allows for the following observations: (1) the largest relative increase appears in the July-September period; (2) the largest increase in absolute values is encountered in the October-December period; (3) negative changes (reductions) are found in periods January-March and April-June due to the fact that more water appears as direct runoff in early months of the hydrological year, which is no longer available in later seasons.

Last, mean six-month flow rates showed the following features: (1) the largest increase appears in the wet semester (October-March); (2) no negative changes are found because the positive values outweigh the negative ones; (3) the increase in flow rate follows the increase in the burnt area for reasons explained above.

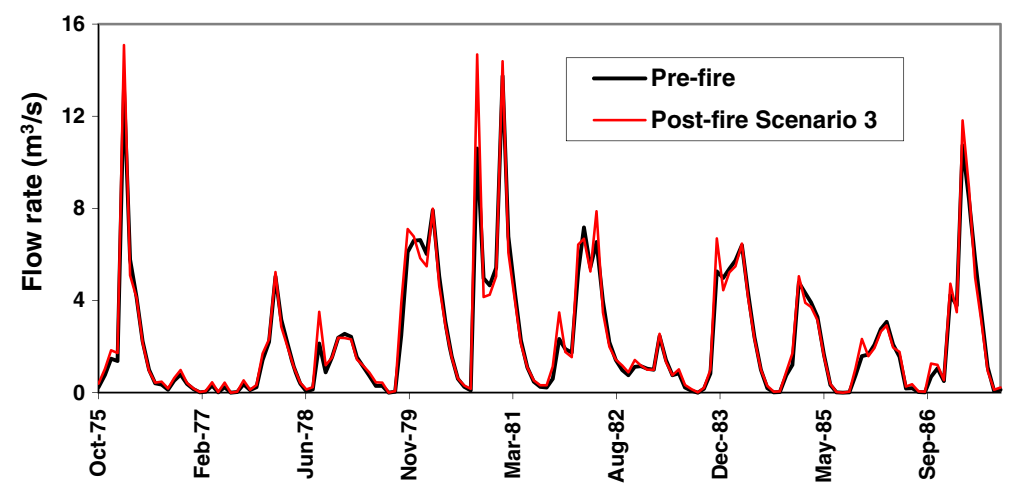

Fig. 5 Simulated flow rate before and after the fire for Scenario 3 

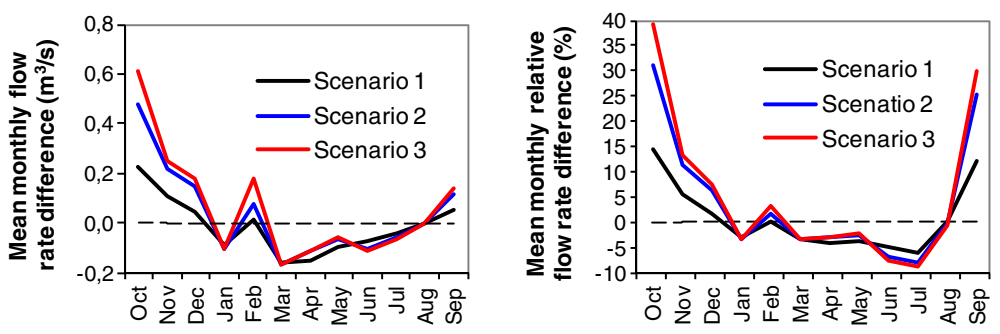

Fig. 6 Mean monthly differences of simulated flow rates (post-fire values minus corresponding pre-fire values) in absolute values (left) and relative values (right)

It is also interesting to see what the effect of fires is with regard to various components of the basin water balance. In this work, we focused on runoff components, namely the direct surface runoff, baseflow, interflow and total runoff (the latter being used for comparison purposes). Changes in these components are given in Fig. 7. The following remarks can be made: (1) Direct surface runoff is progressively increasing from Scenario 1 to Scenario 3, with its maximum increases in February and October; (2) baseflow is essentially unchanged for the period from June to November, whereas for the period December to May it decreases for all scenarios due to the increase of direct runoff and the decrease of infiltration; (3) interflow does not show a consistent behaviour.

\subsection{Effect of Forest Fires on Streamflow in Presence of Drought}

Based on simulated total basin flows before and after each hypothetical fire event, SDI is estimated for each hydrological year and each reference period, as explained in sub-
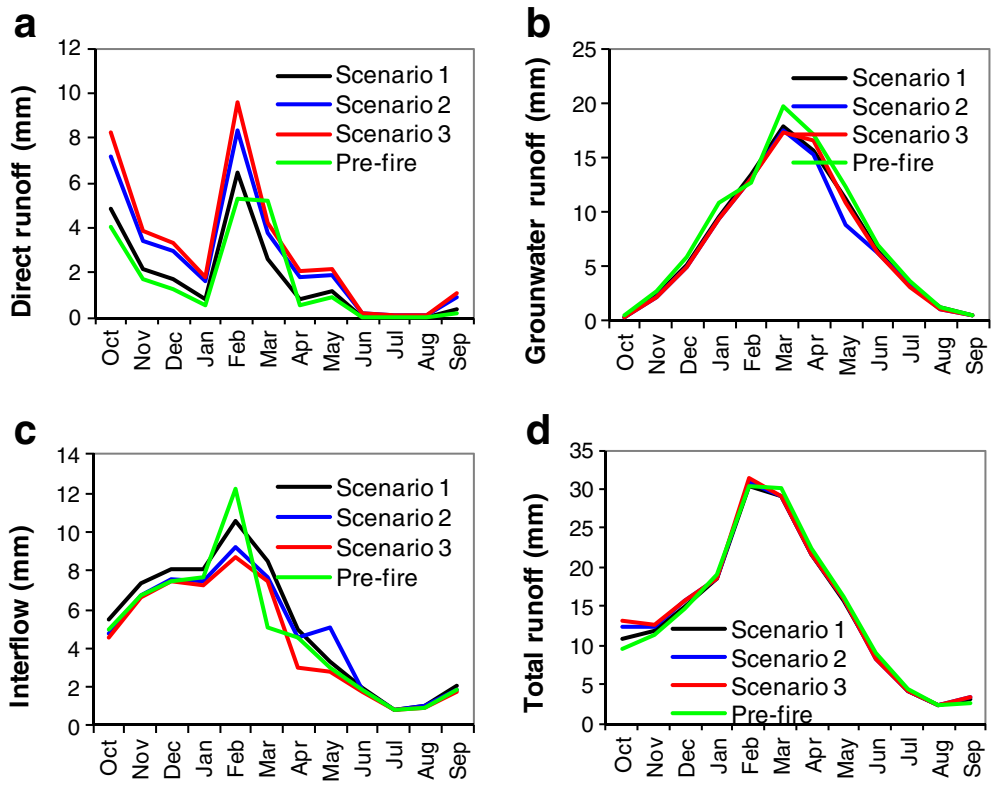

Fig. 7 Mean monthly values of simulated hydrological variables for pre- and post-fire conditions: (a) direct surface runoff; (b) baseflow; (c) interflow; (d) total runoff 
section 2.2. This allows for the estimation of the frequency of occurrence of each drought severity class category. Results depicted in Fig. 8 allow the conclusion that the effect of forest fires on drought classification is minimal since the overall picture of frequency of drought classes is practically unchanged. More specifically, only for the three-month reference period and scenarios 2 and 3 changes in the mean and standard deviation of the flow rate leads to a change in the classification of one hydrological year. This is in the expected direction since larger total runoff values induce a higher frequency of the non-drought class and lower frequency of mild drought.

\section{Conclusions}

The effect of forest fires on the hydrological regime of a drainage basin is studied. Known methodologies and tools such as the Soil Water Assessment Tool (SWAT) are combined to quantify changes in flows that are caused by hypothetical large-scale forest fires. The methodology is illustrated on an example with a medium sized drainage basin in the Mediterranean environment with moderate annual precipitation and significant contribution to runoff from groundwater. Three scenarios of forest fires are constructed, which are typical of fires in the Mediterranean region. It is concluded that: (1) Large-scale forest fires are not expected to significantly modify annual streamflow, which is in accordance with conclusions from earlier studies; (2) increases in monthly streamflow volumes can, however, be high (up to $40 \%$ in our test case); (3) the highest increases appear in months with the highest precipitation (in our test case, October and February); (4) runoff components are influenced to varying

a
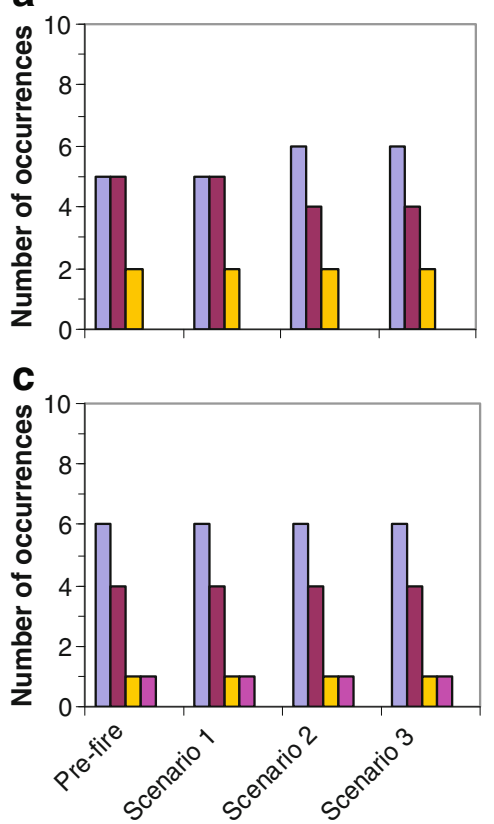

b

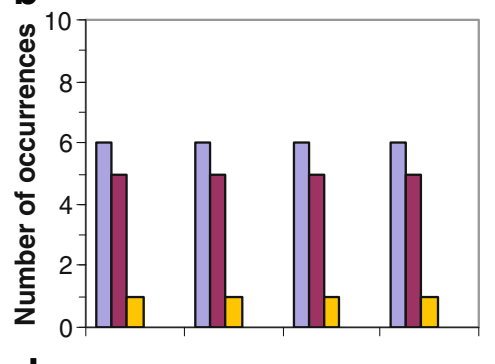

d

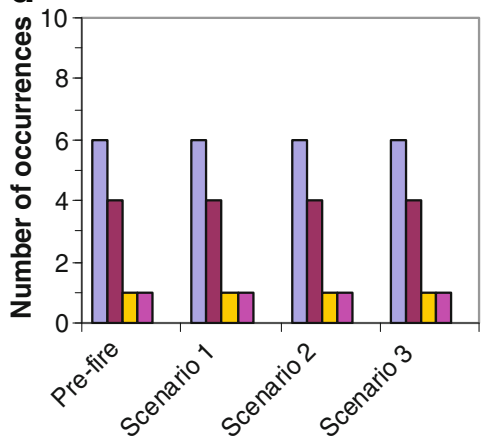

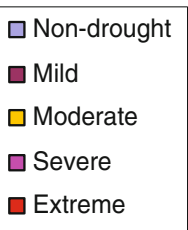

$\square$ Non-drought

$\square$ Mild

$\square$ Moderate

$\square$ Severe

口Extreme

Fig. 8 Number of drought occurrences for pre-fire and post-fire conditions and various reference periods: (a) October-December; (b) October-March; (c) October-June; (d) October-September 
degrees, with the effect on direct surface runoff being the most pronounced; (5) increase of streamflow due to forest fires does not practically affect hydrological drought classification.

Acknowledgements An initial version of this paper was presented at the 8th International Conference of the EWRA in Porto, Portugal, June 26-29, 2013.

\section{References}

Arnold JG, Williams JR, Srinivasan R, King KW (1999) Soil and Water Assessment Tool

Batelis SC (2012) Impact of fires on the water potential of drainage basins: The case of the Enipeas River in Thessaly. Diploma Thesis (in Greek), National Technical University of Athens

Boskidis I, Gikas GD, Pisinaras V, Tsihrintzis VA (2010) Spatial and temporal changes of water quality, and SWAT modeling of Vosvozis river basin, North Greece. J Environ Sci Heal A 45(11): $1421-1440$

Boskidis I, Gikas GD, Sylaios G, Tsihrintzis VA (2011) Water quantity and quality assessment of lower Nestos river, Greece. J Environ Sci Heal A 46(10):1050-1067

Brown AE et al (2005) A review of paired catchment studies for determining changes in water yield resulting from alterations in vegetation. J Hydrol 310:28-61

Cerrelli GA (2005) FIRE HYDRO, a simplified method for predicting peak discharges to assist in the design of flood protection measures for western wildfires, Williamsburg, VA. American Society of Civil Engineers, Alexandria, VA, pp 935-941

Colman EA (1951) Fire and water in southern California's mountains. U.S. For Serv. Calif For Range Exp. Stn. Misc Pap. 3

Gikas GD, Yiannakopoulou Y, Tsihrintzis VA (2006) Modeling of non-point source pollution in a Mediterranean drainage basin. Environ Model Assess 11(3):219-234. doi:10.1007/s10666-005-9017-3

Goodrich DC, Canfield HE, Burns IS, Semmens DJ, Miller SN, Hernandez M, Levick LR, Guertin DP, Kepner WG (2005) Rapid post-fire hydrologic watershed assessment using the AGWA GIS-based hydrologic modelling tool, Proceedings, ASCE Watershed Management Conference, Williamsburg, Virginia, July 1922

Hargreaves GH, Samani ZA (1985) Reference crop evapotranspiration from temperature. Appl Eng Agric 1(2): 96-99

Higginson B, Jarnecke J (2007) Salt Creek BAER-2007 Burned Area Emergency Response, Provo, UT: Uinta National Forest. Hydrology Specialist Report $11 \mathrm{p}$

Livingston RK, Earles TA, Wright KR (2005) Los Alamos post-fire watershed recovery: curve-number-based evaluation, Proceedings, ASCE Watershed Management Conference. Williamsburg, Virginia, July 19-22

Monteith JL (1965) Evaporation and environment. Symp Soc Exp Biol 19:205-234

Nalbantis I, Lymperopoulos S (2012) Assessment of flood frequency after forest fires in small ungauged basins based on uncertain measurements. Hydrolog Sci J 57(1):52-72

Nalbantis I, Tsakiris G (2009) Assessment of hydrological drought revisited. Water Resour Manage 23(5):881897. doi:10.1007/s11269-008-9305-1

Nash JE, Sutcliffe JV (1970) River flow forecasting through conceptual models, I. A discussion of principles. J Hydrol 10(3):282-290

Neitsch SL, Arnold JG, Williams JR (1999) Soil and Water Assessment Tool User's Manual. Texas, USA

Neitsch SL, Arnold JG, Kiniry GR, Williams JR (2005) Soil and Water Assessment Theoretical Tool Documentation. Texas, USA

Pikounis M, Varanou E, Baltas E, Dassaklis A, Mimikou M (2003) Application of the SWAT model in the Pinios River basin under different land-use scenarios. Global Nest 5(2):71-79

Priestley CHB, Taylor RJ (1972) On the assessment of surface heat flux and evaporation using large-scale parameters. Mon Wea Rev 100:81-92

Rycroft HB (1947) A note on the immediate effects of veldburning on stormflow in a Jonkershoek catchment. J S Afr For Assoc 15(80):85

Scott DF (1993) The hydrological effects of fire in South African mountain catchments. J Hydrol 150(2-4):409432 
U.S. Soil Conservation Service (1986) Urban Hydrology of Small Watersheds, Tech. Release 55. U.S. Department of Agriculture, Washington, D.C.

Solt A, Muir M (2006) Warm fire hydrology and watershed report. Richfield, UT: U.S. Department of Agriculture, Forest Service, Intermountain Region, Fishlake National Forest 9 p

Tsakiris G, Vangelis H (2005) Establishing a drought index incorporating evapotranspiration. European Water 9(10):3-11

Tsakiris G, Pangalou D, Vangelis H (2007) Regional drought assessment based on the reconnaissance drought index (RDI). Water Resour Manage 21(5):821-833. doi:10.1007/s11269-006-9105-4 